\title{
A study of maternal mortality in Government Maternity Hospital, Sri Venkateswara Medical College, Tirupati
}

\author{
J Sowjanya Kumari ${ }^{1, *}$, V Revathi ${ }^{2}$, K Sharmista Reddy ${ }^{3}$ \\ ${ }^{1}$ Professor and HOD, ${ }^{2}$ Professor, ${ }^{3}$ Post Graduate, Dept. of Obstetrics and Gynecology, Sri Venkateswara Medical College, \\ Tirupati, Andhra Pradesh, India
}

*Corresponding Author: J Sowjanya Kumari

Email: dr.sowjanyakumari@gmail.com

Received: $28^{\text {th }}$ August, 2018

Accepted: $9^{\text {th }}$ October, 2018

\begin{abstract}
Introduction: Maternal mortality is a key indicator of health services provided to population and reflects the health status of community.

Aim: To study the factors responsible for maternal mortality.

Materials and Methods: Maternal deaths that occurred in one year in Government Maternity Hospital, Tirupati were studied. Present study was conducted from January 2017 to December 2017 in Department of Obstetrics \& Gynaecology, Government Maternity Hospital, S.V. Medical College, Tirupati.

Results: 21 maternal deaths had occurred during the study period. $57.1 \%$ were unbooked cases, $61.9 \%$ were primiparous women and $61.9 \%$ were belonging to the age group of 21-25 years. Leading cause of death was hypertensive disorders of pregnancy (47.6\%) followed by postpartum haemorrhage (28.4\%). Maternal deaths due to direct causes were $85.7 \%$ and indirect causes were $14.3 \%$. type 2 and 3 delays contributed to $57.1 \%$ and $38.1 \%$ maternal deaths respectively. Most of the cases were referred to the institute in late stages.

Conclusion: Health education, regular antenatal check ups, early identification of high risk pregnancies and timely intervention are needed to reduce maternal mortality.
\end{abstract}

Keywords: Hypertensive disorders of pregnancy, Maternal mortality, Postpartum haemorrhage.

\section{Introduction}

Maternal death is defined as death that can occur as a direct result of obstetric complications or indirectly due to pregnancy-induced aggravation of pre-existing medical conditions, but not due to incidental or accidental causes. ${ }^{1}$ The same was defined and classified according to WHO international classification of diseases, 10th revision. ${ }^{2,3}$ Direct maternal deaths are caused by pregnancy, labour and puerperium. Indirect deaths are caused by previously existing disease or disease that developed and/or increased during pregnancy. Maternal mortality ratio is defined as the number of maternal deaths that occurred per 1 lakh live births up to 42 days after the termination of pregnancy. ${ }^{1,4}$ Inspite of marked fall in maternal mortality in recent years, every day about 830 women die from pregnancy or childbirth-related causes. These deaths are preventable. Goal of United Nations is to reduce MMR by $75 \%$ by $2015 .{ }^{5}$ There is a wide variation in MMR in India and variations in the regional states. Multiple factors like social factors, economic status, literacy, patient care, hospital care, infrastructure facilities in the referral units etc has its impact on maternal death. The United Nations Population Fund (UNFPA), 2017 report is as follows: one woman dies every two minutes and 20 to 30 women have suffer with severe morbidity for every one woman who dies. ${ }^{6}$ Global ratio of maternal mortality is 400 per one lakh live births. India has made significant progress in reducing maternal mortality. MMR ratio has declined from 556 per one lakh live births in the year
1990 to 167 in 2011-13 and 130 per one lakh live births in the year 2016. ${ }^{6}$ Approximately 44000 maternal deaths occur in India. Millennium Development Goals mandate a further reduction in MMR to 103. Maternal death review process initiated by the Government of India in 2010 by analysing and identifying lacunae in the healthcare systems to improve the quality of obstetric services. ${ }^{7}$ Approximately 1.4 lakh women die every year. The target of MMR set for India was 139 per one lakh live births. This had to be achieved by the year 2015 and India has achieved MMR of 130 per one lakh live births by the year 2016. ${ }^{7}$ As per sustainable developmental goals India has aimed to reducing MMR to less than 70 per one lakh live births. ${ }^{7}$

The various states in India have a stark contrast in MMR. Among the south Indian states, Kerala has the least MMR with 46 per 1 lakh live births for the year 2016. Andhra Pradesh has reduced MMR from 92 per one lakh live births in year 2013 to 74 per one lakh live births in year 2016. Among all the states Assam has highest MMR of 237 per one lakh live births in the year $2016 .^{8}$

Main causes of maternal mortality is postpartum haemorrhage $(27.1 \%)$ worldwide. Indirect causes of maternal deaths are anemia, malaria, heart disease (27.5\%), infection (10.7\%), unsafe abortions (7.9\%), hypertensive disorders (14\%), obstructed labour, ectopic pregnancy, embolism (3.2\%) and anaesthesia complications. $45 \%$ of postpartum haemorrhage occur within first 24 hours. $66 \%$ occur during first week. ${ }^{9}$ 
In developing countries MMR has been attributed to three delays-type 1 . Delay in deciding to seeking care, type 2. Delay in time taken to reach the health care facility Type 3 . Delay in receiving care at the health facility. ${ }^{10}$

Government Maternity Hospital, Tirupati is a tertiary care centre receiving high risk and moribund patients. It is a referral centre for four districts and prestigiously known as Institute for Pregnant women. In Government Maternity Hospital, S.V. Medical College, Tirupati, 22 deaths occurred during the year 2015 and 13 deaths during the year 2016. The present study has been taken up to analyse causes with an aim to reduce preventable deaths.

\section{Aim}

To analyse and assess the direct and indirect obstetric factors involved in maternal mortality aimed to prevent maternal deaths and to provide safety measures to reduce maternal morbidity.

\section{Objectives}

1. To analyse the specific causes of maternal mortality in Government Maternity Hospital, Tirupati.

2. To identify the factors causing maternal deaths in this institute.

3. To identify the leading cause of death in our institution during the study period.

4. To identify the requirements and deficiencies in the management of preventable deaths in this institute.

\section{Materials and Methods}

Study Method: Observational study

Study Setting: Department of Obstetrics and Gynaecology, Government Maternity Hospital, S.V. Medical College, Tirupati.

Study Period: period of study is from 1 January 2017 to 31 December 2017.

Study Population: maternal deaths recorded during the one year period i.e. from January 1, 2017 to December 31, 2017 were 21. Total 64,299 antenatal cases were treated by the Department of Obstetrics and Gynaecology during the study year. Total number of deliveries were conducted during the year were 12,276, out of which 7,348 were normal vaginal deliveries, 1454 were instrumental vaginal deliveries and 3424 were caesarean sections. These deliveries resulted in 12,134 live births during the year 2017 i.e. from January to December.

Methodology: Data was collected from the cases admitted in the Department of Obstetrics \& Gynaecology, Government Maternity hospital, S.V. Medical College, Tirupati were followed and studied. An analysis was done in the departmental MMR reviews with the involvement of professors, associate professors and assistant professors, department of anesthesiology, department of medicine and transfusion medicine. All cases were followed and analysed on demographic factors, social, obstetric factors, therapeutic factors and analysis of specific causes and leading cause of maternal mortality and identification of the level of delay done. Data was subsequently recorded in Microsoft Excel 2013 and analysed using descriptive statistics.

\section{Results}

Government Maternity Hospital of S.V. Medical College, Tirupati provided antenatal services both OP and IP to 64,299 antenatal women during the period of January 1, 2017 to December 31, 2017. During this period a total of 12,276 deliveries were conducted. Total number of live births were 12,134 during the study period. 21 maternal deaths occurred during the study period. 1 case of death remained inconclusive due to the failure of diagnosis of pregnancy in that specific case. The MMR in this institute is 173 per 1,00,000 live births.

According to Kuppuswamy scale of socio-economic classification based on education, occupation and income the socio economic status of women were categorised. ${ }^{11} 90.4 \%$ of them belonged to class $\mathrm{V}$ and $19.6 \%$ belonged to class IV.

$61.9 \%$ belonged to $20-25$ years age group and were primipara. Direct causes are responsible for $85.7 \%$ of maternal mortality. $54.6 \%$ maternal deaths were due to hypertensive disorders and it is the leading cause of death in this institute. The other common cause of maternal death is haemorrhage. Most of the deaths in the institute occurred due to late referral.

Table 1: Booked vs unbooked

\begin{tabular}{|l|c|c|}
\hline Booked & 9 & $42.9 \%$ \\
\hline Unbooked & 12 & $57.1 \%$ \\
\hline
\end{tabular}

Out of 21 cases of maternal deaths, $12(57.1 \%)$ cases were unbooked and had received poor antenatal care

Table 2: Age distribution

\begin{tabular}{|l|c|c|}
\hline age $<\mathbf{2 0}$ & $\mathbf{5}$ & $\mathbf{2 3 . 8 \%}$ \\
\hline $21-25$ & 13 & $61.9 \%$ \\
\hline $26-30$ & 2 & $9.5 \%$ \\
\hline $31-35$ & 1 & $4.8 \%$ \\
\hline
\end{tabular}

Majority of the women $13(61.9 \%)$ were in the age group of 21-25 years. 5(23.8\%) were below 20 years. Youngest of them was a mere 15-year-old teenage girl.

Table 3: Parity distribution

\begin{tabular}{|l|c|c|}
\hline Primi & 13 & $61.9 \%$ \\
\hline Multi & 8 & $38.1 \%$ \\
\hline
\end{tabular}

$13(61.9 \%)$ were primiparous and $8(38.1 \%)$ multiparous. 5 women were second gravida, 2 women were third gravida and one woman was fourth gravida. 
Table 4: Mode of delivery

\begin{tabular}{|l|c|c|}
\hline Vaginal & 2 & $9.5 \%$ \\
\hline Assisted vaginal & 2 & $9.5 \%$ \\
\hline Abnormal vaginal & 2 & $9.5 \%$ \\
\hline Hysterotomy & 1 & $4.8 \%$ \\
\hline Caesarean section & 13 & $61.9 \%$ \\
\hline Undelivered & 1 & $4.8 \%$ \\
\hline
\end{tabular}

$13(61.9 \%)$ cases where deaths occurred were delivered by caesarean section. Indications for caesarean sections being performed were post caesarean pregnancies and causes like eclampsia where immediate termination of pregnancy was warranted. 6 cases were delivered by the vaginal route. $2(9.5 \%)$ were delivered by normal vaginal delivery, $2(9.5 \%)$ were delivered by abnormal vaginal delivery owing to prematurity of the fetus and $2(9.5 \%)$ were delivered by assisted vaginal delivery. $1(4.8 \%)$ case was delivered by hysterotomy. $1(4.8 \%)$ case died undelivered.

Table 5: Cause distribution

\begin{tabular}{|l|c|c|}
\hline Anemia & 16 & $76.2 \%$ \\
\hline Pre eclampsia & 7 & $33.3 \%$ \\
\hline Eclampsia & 3 & $14.3 \%$ \\
\hline HELLP & 2 & $9.5 \%$ \\
\hline PPH & 6 & $28.6 \%$ \\
\hline pulmonary edema & 6 & $28.6 \%$ \\
\hline sepsis & 3 & $14.3 \%$ \\
\hline pulmonary embolism & 5 & $23.8 \%$ \\
\hline AF embolism & 1 & $4.8 \%$ \\
\hline APH & 1 & $4.8 \%$ \\
\hline medical complications & 9 & $42.9 \%$ \\
\hline post op complications & 2 & $9.5 \%$ \\
\hline DIC & 3 & $14.3 \%$ \\
\hline blood reaction & 1 & $4.8 \%$ \\
\hline
\end{tabular}

Table 6: Direct and indirect cause of maternal death

\begin{tabular}{|l|c|c|}
\hline Direct cause & 18 & $85.7 \%$ \\
\hline Indirect cause & 3 & $14.3 \%$ \\
\hline
\end{tabular}

$85.7 \%$ maternal deaths were due to direct causes and $14.3 \%$ were due to indirect causes. Direct causes of death are postpartum haemorrhage (6), infection (3), embolism (6) and eclampsia (3).

Table 7: Type of delay

\begin{tabular}{|l|c|c|}
\hline Type 1 & 1 & $4.8 \%$ \\
\hline Type 2 & 12 & $57.1 \%$ \\
\hline Type 3 & 8 & $38.1 \%$ \\
\hline
\end{tabular}

\section{Discussion}

All the maternal deaths that occurred were of women who belonged to the low socio-economic group. 20 of the 21 maternal deaths occurred after delivery and one case died during the antenatal period. Most of the cases were unbooked cases $(57.1 \%)$ which showed the importance of antenatal care in preventing maternal death.

In the present study $90.4 \%$ women belonged to lower socio-economic group according to Kuppuswamy scale and $19.6 \%$ were of the upper lower category. Most of the maternal deaths were among women belonging to poor class $(76.4 \%) .{ }^{11}$ Literacy, parity and socioeconomic status are some of the determinants of maternal mortality and can act as risk factors if are on the unfavourable side. ${ }^{1}$

Primiparous $(61.9 \%)$ women are at more risk of maternal mortality. $85.7 \%$ of maternal mortality is due to direct causes which include pre-eclampsia, eclampsia, PPH and antepartum haemorrhage.

Deaths due to hypertensive disorders of pregnancy were the leading cause with $10(47.6 \%)$ of the 21 maternal deaths due to pre-eclampsia, eclampsia and HELLP syndrome. HELLP syndrome complicated 3 cases of severe pre-eclampsia and eclampsia. WHO and Government of India have listed haemorrhage as number one cause of death but in the present institute, hypertensive disorders formed a major share. This may be due to the present institute being a referral centre and receiving a large number of cases of hypertensive disorders of pregnancy in late stages. Younger age women are vulnerable to develop hypertensive disorders and maternal mortality.

Postpartum haemorrhage, the leading cause of maternal deaths worldwide was a direct cause of death in 6 mothers during the study period. Introduction of SR cannula for prevention and control of atonic PPH during later end of the year had a significant impact in reducing morbidity and mortality due to PPH. 4 cases of atonic PPH were recorded, 1 death was due to traumatic PPH and another due to coagulation abnormalities causing uncontrolled haemorrhage.

Sepsis as the cause of death was observed in 3 women and antepartum haemorrhage in 1. Postoperative complications were observed in 2 women who died. Pulmonary embolism, amniotic fluid embolism and medical complications were the cause in 5,1 and 9 maternal deaths. Adverse blood transfusion reaction was responsible for 1 maternal death which had a renal failure due to the same and was referred to the present institute.

18 of the 21 mothers had live babies at delivery. 2 were delivered stillborn and 1 women died undelivered.

Anaemia the leading and precipitating indirect cause of a number of obstetric complications was identified in $16(76.2 \%)$ women. Anaemia is an easily modifiable risk factor which if corrected can avert a number of maternal deaths. A large number of programmes are launched and implemented by Government of India like weekly iron and folic acid prophylaxis programme, parenteral iron therapy at $\mathrm{PHC}$ and $\mathrm{CHC}$ level, provision of diet to antenatal mothers and iron prophylaxis with IFA tablets with an aim of early detection and correction of anaemia. 
In the majority of the cases (16), death occurred due to multiple obstetric and medical complications one leading to another.

A large number of women belonged to the age group of 21-25 years (61.9\%). However other studies like Oladapo et al reported a higher maternal mortality in elderly women. ${ }^{12}$ The disparity may be due to cultural differences regarding age at marriage and conception in India which is at a relatively younger age compared to other countries.

Majority of the women in the present study were primiparous at death $(61.9 \%)$. The results are higher when compared to study by Oladapo et al. where one third women were primiparous and similar to results in study by Paul B et al ${ }^{12,13}(55.8 \%)$.

The leading cause of death in the present study is hypertensive disorders of pregnancy i.e. $47.6 \%$ in the year 2017. The findings are similar to study by Paul B et al which reported first cause of maternal mortality as hypertensive disorders $(30 \%) .{ }^{13}$ However Government of India and WHO report haemorrhage as first cause of maternal mortality. The results can also be compared to study by Oladapo et al who reported leading cause of maternal deaths as hypertensive disorders of pregnancy $(28 \%){ }^{12}$

Direct cause of death is $85.7 \%$ in the present study. This is compared to study by Paul B et al who reported $76.7 \%$ direct causes of maternal mortality in 2006-07. ${ }^{13}$ Haemorrhage, hypertension and sepsis were responsible for more than half of the deaths worldwide. Direct causes of death are postpartum haemorrhage (6), infection (3), embolism (6) and eclampsia (3). In the present institute $5.9 \%$ of cases of postpartum haemorrhage resulted in death out of the recorded 102 cases of major postpartum haemorrhage during 2017.

In the present study type 1, 2 and 3 delays had role in $4.8 \%, 57.1 \%$ and $38.1 \%$ maternal deaths respectively. This is similar to the study by Paul B et al where type 1 and 2 contributed to $58 \%$ maternal deaths and type 3 contributed $46.5 \%$ maternal deaths.

Regular monitoring of blood pressure and detection of albuminuria at primary health care centres with early detection of hypertensive disorders of pregnancy can prevent maternal deaths at facility level. Early referral must be done to tertiary care centres where blood transfusion, ventilator facilities and dialysis units are available.

Interventions to reduce MMR are by increasing quality care services. Interventions are

1. Target the main cause of death.

2. Improving antepartum, intrapartum and postpartum care.

3. Antenatal care is the key to identify high risk pregnancies

4. Efficiently treating the intrapartum complications at health care facility i.e. trating PPH, administering oxytocics, blood transfusion and availability of surgical interventions and treatment of eclampsia.
5. Professional skilled birth attendants available during labour.

6. Develop access to safe abortions under specific considerations

7. Improve health care system and implementation of government programmes by providing financial assistance

8. Provision of basic emergency obstetric interventions are vital to improve chances of survival.

Government of India has provided number of schemes to improve maternal health in the form of PMSMA, JSSY for drugs, blood, transportation and early identification of risk factors for direct and indirect causes of maternal mortality at PHC and CHC hospitals for better care of antenatal mother. ${ }^{14}$ Government of India has also provided infrastructure, obstetric ICU, emergency obstetric units and medical personnel at tertiary level to reduce maternal morbidity and mortality. There is also nil tolerance towards home deliveries.

\section{Conclusion}

The present study had aimed to analyse community factors and institutional factors contributing to maternal mortality. Hypertensive diseases of pregnancy presented as the most common cause of maternal mortality. Early antenatal care, health education, identification of hypertension at an early gestational age and timely intervention can reduce maternal morbidity and mortality. Postpartum haemorrhage can be controlled by active management of third stage of labour and employing newer techniques like SR cannula. ${ }^{15}$ Lack of life support equipment, ventilator and dialysis units with non-availability of blood products have contributed to maternal mortality. Services of experienced medical personnel where essential services are needed to identify high risk factors to reduce maternal mortality.

\section{References}

1. Park K. Park's Textbook of Preventive and Social Medicine, $20^{\text {th }}$ ed. 2009. p. 450,482,556-7.

2. Government of India (Sample Registration System). Maternal Mortality in India: 1997-2003, trends, causes and risk factors, Registrar General, India, New Delhi in collaboration with Centre for Global Health Research, Toronto, ON, Canada.

3. World Health Organization: ICD-10: International statistical classification of diseases and health-related problems. Tenth Revision. 1993, Geneva: World Health Organization, 2

4. Cunningham F. G, Leveno K. J, Bloom S. L., Spong C. Y., Dashe J. S., Hoffman B. L., Casey B.M., Sheffield J. S. (2014). Williams obstetrics (24th edition.). New York: McGraw-Hill Education. chapter 1, page 3.

5. Haines A, Cassels A: Can Millennium Development Goals be attained?. BMJ. 2004;329:394-397. 10.1136/bmj.329.7462.394

6. Trends in maternal mortality: 1990-2015 WHO, UNICEF, UNFPA, World Bank Group and the United Nations Population Division estimates 
7. Guidelines for maternal death surveillance $\&$ response 2017. Ministry of health \& family welfare, Government of India. Chapter-1,page no.2.

8. special bulletin on maternal mortality in India 2014-16, sample registration system, May 2018.

9. Lale Say, Doris Chou, Alison Gemmill, Özge Tunçalp, Ann-Beth Moller, Jane Daniels, A Metin Gülmezoglu, Marleen Temmerman, Leontine Alkema. Global causes of maternal death: a WHO systematic analysis. Lancet Glob Health. 2014;2:e323-33.

10. Thaddeus S, Maine D. Too far to walk: maternal mortality in context. Soc Sci Med. 1994;38:1091-1100.

11. Bedi N, Kambo I, Dhillon BS, Saxena BN, Singh P. Maternal deaths in India: Preventable Tragedies (An ICMR Task Force Study). J Obstet Gynecol Ind. 2001;51:86-92.

12. Oladapo OT, Lamina MA, Fakoya TA. Maternal deaths in Sagamu in the new millennium: a facility based retrospective analysis. BMC Pregnancy and child birth 2006, 6:6
13. Biswajit Paul, Bijeeyani Mohapatra, Krishna Kar. Maternal Deaths in a Tertiary Health Care Centre of Odisha: An In-depth Study Supplemented by Verbal Autopsy. Indian J Community Med. 2011;36(3):213-216.

14. Pradhan Mantri Surakshit Matritva Abhiyan. Maternal Health Division. Ministry of Health and Family Welfare. 2016. Page 1-19.

15. Samartha Ram H., Shankar Ram HS, Sandhya Ram S, Vasudeva Panicker. Vacuum retraction of uterus for the management of atonic postpartum hemorrhage. IOSR Journal of Dental and Medical Sciences (IOSR-JDMS). 2014;13(11)Ver. III:15-19.

How to cite this article: Kumari J S, Revathi V, Reddy K S. A study of maternal mortality in Government Maternity Hospital, Sri Venkateswara Medical College, Tirupati. Indian J Obstet Gynecol Res. 2018;5(4):525-529. 